\title{
Effects of Hemin on Heme Oxygenase-1, Gastric Emptying, and Symptoms in Diabetic Gastroparesis
}

\author{
Adil E. Bharucha, M.B.B.S., M.D., Shannon L. Daley ${ }^{1}$, Phillip A Low, M.D. ${ }^{2}$, Simon J. \\ Gibbons, Ph.D. ${ }^{3}$, Kyoung Moo Choi, Ph.D. ${ }^{3}$, Michael Camilleri ${ }^{1}$, essica J. Saw ${ }^{4}$, Gianrico \\ Farrugia, M.D. ${ }^{1}$, and Alan R Zinsmeister, Ph.D. ${ }^{5}$ \\ ${ }^{1}$ Enteric Neurosciences Program, Division of Gastroenterology and Hepatology, Department of \\ Medicine, Mayo Clinic, Rochester, MN \\ ${ }^{2}$ Department of Neurology, Mayo Clinic, Rochester, MN \\ ${ }^{3}$ Department of Physiology and Biomedical Engineering, Mayo Clinic Center for Biomedical \\ Discovery, Rochester, MN \\ ${ }^{4}$ Mayo Medical School, Mayo Clinic College of Medicine, Rochester, MN \\ ${ }^{5}$ Division of Biomedical Statistics and Informatics, Department of Health Sciences Research, \\ Mayo Clinic, Rochester, MN
}

\begin{abstract}
Background-Therapeutic options for management of diabetic gastroparesis are limited. Failure to maintain upregulation of heme oxygenase (HO1) leads to loss of interstitial cells of Cajal and delayed gastric emptying in non-obese diabetic (NOD) mice. Our hypothesis was that hemin upregulation of $\mathrm{HO} 1$ would restore normal gastric emptying in humans with gastroparesis.
\end{abstract}

\begin{abstract}
Aims-To compare effects of hemin and placebo infusions on HO1 activity and protein, gastric emptying, autonomic function, and gastrointestinal symptoms in diabetic gastroparesis.

Methods-In a single-center, double-blind, placebo-controlled, randomized clinical trial, we compared intravenous hemin, prepared in albumin, or albumin alone (placebo) in 20 patients, aged $41 \pm 5$ (SEM) years with diabetic gastroparesis. After infusions on days 1, 3, and 7, weekly infusions were administered for 7 additional weeks. Assessments included blood tests for HO1 protein and enzyme activity levels, gastric emptying with ${ }^{13} \mathrm{C}$-spirulina breath test, autonomic functions (baseline and end), and gastrointestinal symptoms every 2 weeks.
\end{abstract}

\footnotetext{
Address for correspondence and reprint requests: Adil E. Bharucha, M.D., Clinical Enteric Neuroscience Translational and Epidemiological Research Program (C.E.N.T.E.R.), Mayo Clinic, 200 First St. S.W., Rochester, MN 55905, Telephone: 507-538-5854; Fax: 507-538-5820; bharucha.adil@ mayo.edu.

Disclosures: None of the authors have any conflicts of interest that are relevant to the manuscript.

Author contributions: Study concept and design: Bharucha, Camilleri, and Farrugia.

Acquisition of data: Bharucha, Daley, Low,

Analysis and interpretation of data: Bharucha, Gibbons, Choi, Farrugia, and Saw

Drafting of the manuscript: Bharucha

Critical revision of the manuscript for important intellectual content: All authors

Statistical expertise: Zinsmeister.

Obtained funding and study supervision: Bharucha.
} 
Results-Nine of 11 patients randomized to hemin completed all study procedures. Compared to placebo, hemin increased HO1 protein on days $3(P=.0002)$ and $7(P=.008)$ and HO1 activity on day 3 ( $P=.0003$ ) but not after. Gastric emptying, autonomic functions, and symptoms did not differ significantly in the hemin group relative to placebo.

Conclusions-Hemin failed to sustain increased HO1 levels beyond a week and did not improve gastric emptying or symptoms in diabetic gastroparesis. Further studies are necessary to ascertain whether more frequent hemin infusions or other drugs would have a more sustained effect on $\mathrm{HO} 1$ and improve gastric emptying.

\section{Graphical abstract}

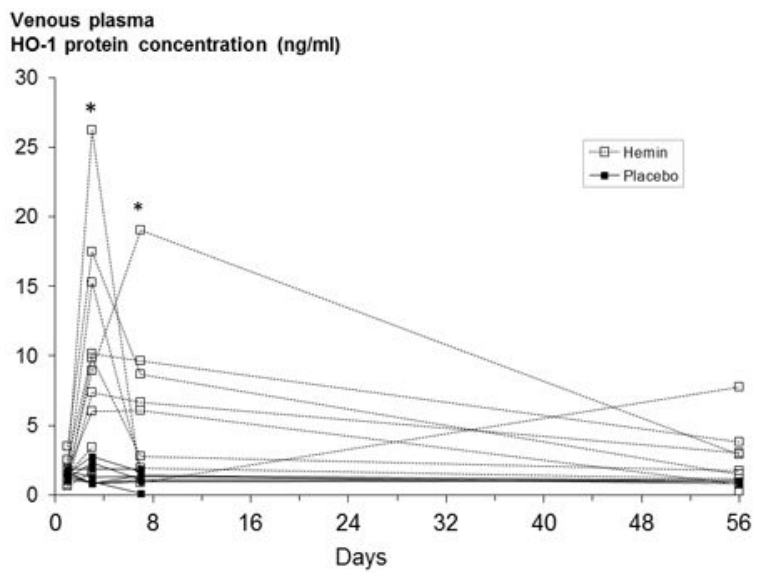

\section{Keywords}

heme oxygenase; hemin; $\mathrm{HO}$; humans

Diabetic gastroparesis is common, particularly in tertiary medical centers, can significantly impact quality of life, and is associated with morbidity and mortality $(1,2)$. Management of diabetic gastroparesis is based upon the severity of symptoms and includes optimization of glycemic control, oral or, if necessary, enteral nutritional supplementation, prokinetic and symptomatic therapies, particularly antiemetic agents, and gastric electrical stimulation (3). However, the long-term use of prokinetic drugs (e.g., metoclopramide, domperidone, and erythromycin) is limited by concerns regarding safety and efficacy (3). Moreover, current therapeutic options do not address the underlying putative pathophysiological mechanisms or the pathogenesis of the same (e.g., oxidative stress). Given the absence of treatments that can restore normal vagal function in patients with diabetes, we sought the opportunity to address loss of enteric nerve function and interstitial cells of Cajal (ICC), which are the 2 main cellular defects in diabetic gastroparesis (4-6).

Oxidative stress, which results from an imbalance between production of reactive oxygen species and anti- oxidant defenses such as catalase, superoxide dismutase, and heme oxygenase, together with macrophage activation, has been implicated in the pathogenesis of diabetic peripheral and autonomic neuropathy and enteropathy (7-9). In diabetic non-obese diabetic (NOD) mice, failure to maintain upregulation of the protective expression of heme 
oxygenase 1 (HO1) in macrophages in response to oxidative stress appears to be responsible for loss of ICC and development of delayed gastric emptying (GE) (10). The numbers of ICC correlate with GE in diabetic gastroparesis (4). Upregulation of HO1 by hemin in diabetic NOD mice reversed delayed GE in this animal model (10). Heme oxygenase (HO) is the rate limiting enzyme in the catabolism of heme, generating equimolar amounts of biliverdin, free iron, and carbon monoxide (CO) (11). Of the 2 functional $\mathrm{HO}$ isoforms in mammals, $\mathrm{HO} 2$ is a constitutively expressed enzyme with an important role in neuronal function (12). Expression of HO1 is normally low to undetectable except in tissues involved in erythrocyte metabolism (i.e., liver and spleen). When HO1 is induced, the end products of heme metabolism (CO, iron, and biliverdin) are generated (12). Among the metabolic products of heme, $\mathrm{CO}$ exerts vasorelaxant, anti-apoptotic, and anti-inflammatory effects. Exogenous CO delivered at $100 \mathrm{ppm}$ reverses delayed GE in diabetic NOD mice, suggesting it may be the key mediator of the effects of HO1 (13). Biliverdin, another product of heme metabolism, is antioxidant, anti-inflammatory, protects against endothelial damage, and reduces atherogenic risk (11).

There are no orally-administered agents known to upregulate HO1 in humans; a combination aspirin, simvastatin, and alpha lipoic acid did not increase leukocyte HO1 activity in humans (14). Hemin is one of the most powerful inducers of HO1 known (15). We previously demonstrated that intravenous hemin administration upregulated HO1 in humans (16). While hemin is FDA-approved to treat acute intermittent porphyria, it has also been used to treat thalassemia intermedia, myelodysplastic syndrome, and to control liver allograft failure due to recurrence of erythopoietic protoporphyria (17-21).

Our hypothesis was that compared to placebo, hemin would increase HO1 and GE and improve symptoms in patients with diabetic gastroparesis. The objectives of this study were to evaluate the effects of hemin on HO1 protein levels and activity, symptoms, and GE in patients with diabetic gastroparesis.

\section{Materials and Methods}

This was a single-center, double-blind, placebo-controlled, randomized clinical trial at Mayo Clinic, Rochester, MN comparing the effects of intravenous hemin and placebo in diabetic patients with gastroparesis. Drug infusions were given and GE was measured on days 1, 4, 7, 14, 21, 28, 35, 42, 49, and 56 (Figure 1). The HO1 protein concentration and activity were measured on these days and also on day 3. Symptoms and autonomic functions were assessed as described below. The study was approved by the Mayo Clinic Institutional Review Board, and all participants signed informed consent. This study was registered on Clinical Trials.gov (NCT01206582).

\section{Participants}

Between May 2010 and November 2013, we enrolled 20 diabetic patients with gastroparesis, aged 20-73 years (mean $[ \pm$ SEM] age 41 [ \pm 5 years]) who were referred for consideration of participation in this study or responded to public advertisement; 18 participants were women. The trial ended when all participants were enrolled. Subjects were screened by a clinical assessment, laboratory tests, and questionnaires to exclude functional 
gastrointestinal (GI) disorders, anxiety, and depression (22, 23). Additional exclusion criteria included previous gastric or intestinal surgery, current use of narcotics or anticholinergic agents, venous thrombosis or hypercoagulable state, and poor peripheral venous access. The inclusion criteria were delayed GE as measured by scintigraphy (24); moderately severe symptoms as manifested by a total symptom score of 2.5 or higher on any of 3 subscales of the Gastroparesis Cardinal Symptom Index (GCSI); absence of a gastroduodenal structural cause for symptoms on upper GI endoscopy in the past 12 months; platelet count of 50,000/ microliter or higher; absolute neutrophil count of 500/microliter or higher and a creatinine $<1.7 \mathrm{mg} / \mathrm{dL}$; and serum bilirubin, serum glutamic-oxaloacetic transaminase (SGOT), and serum glutamate pyruvate transaminase (SGPT) each less than 2-fold the upper limit of normal. Gastrointestinal prokinetic drugs (e.g., metoclopramide) were permitted provided they were continued at a stable dose throughout the study.

\section{Hemin}

During the treatment period, participants were evenly randomized to placebo or hemin; randomization was balanced on gender, estimated glomerular filtration rate ( $<60$ or $\ 60 \mathrm{~mL}$ / minute $/ 1.73 \mathrm{~m}^{2}$ ) and C-peptide concentration (< or $\searrow 0.6 \mathrm{ng} / \mathrm{mL}$ ). The randomisation was generated by the study statistician with a computer and sent to the research pharmacy. Study personnel were blinded until the study was completed. All clinical and laboratory study personnel were blinded throughout the study until all data were analyzed. When prepared in sterile water, hemin is highly unstable, and only $50 \%$ of the active ingredient remains after 5 minutes (25). To enhance stability, hemin was reconstituted with human albumin, which increases its efficacy, prevents its anticoagulant effect, and also reduces the incidence of phlebitis (26). Hemin (Panhematin®, Recordati Rare Diseases) was diluted in $~ 132 \mathrm{~mL}$ of $25 \%$ albumin to obtain a hemin concentration of $2.4 \mathrm{mg} / \mathrm{mL}$ (26) and administered at a dose of $1.25 \mathrm{~mL} / \mathrm{kg}$ and at a rate of $60 \mathrm{~mL} / \mathrm{hour}$. This dose is similar $(3-4 \mathrm{mg} / \mathrm{kg})$ to that recommended for treating acute porphyria (21) and increases HO1 in humans (16). The same volume of albumin alone was administered for placebo infusions. All infusions were prepared by standard practice in the Mayo Clinical Research Unit Research Pharmacy using current American Society of Health-System Pharmacists (ASHP) class III procedures for sterile preparation. Both albumin $25 \%$ and hemin/albumin $25 \%$ were filtered using a 5 micron disc filter. The bottle and tubing were shrouded with amber light-resistant plastic to assist blinding of the patient and study team.

\section{Measurement of HO1 Protein Concentration and Activity}

As described previously, $\mathrm{HO} 1$ protein concentration levels in plasma were assessed with a HO1 (human) enzyme-linked immunosorbent assay (ELISA) kit (Assay Designs Inc. Ann Arbor, MI) (16). HO1 activity in white blood cells was measured by an assay that measures bilirubin production as a marker of $\mathrm{HO} 1$ activity $(16,27)$. These assays were performed at baseline, on day 3, before and after hemin infusions on days 4 and 7, and after infusions on days $14,21,28,35,42,49$, and 56. On days that the assays were performed after the hemin infusion, blood samples were collected concurrently with the 3 hour gastric emptying breath sample, i.e., approximately 3 hours after the infusion was completed. To reduce multiple comparisons, $\mathrm{HO} 1$ data from baseline, days 3 and 7 and day 56 were analyzed. 


\section{Assessment of GE with ${ }^{13} \mathrm{C}$ Spirulina Breath Test}

All breath tests were performed in the morning after an overnight fast. The first breath test provided a baseline value and was performed in the early morning before the first drug infusion; the other $9 \mathrm{GE}$ breath tests (GEBT) were performed after drug or placebo infusions on days 4, 7, 14, 21, 28, 35, 42, 49, and 56. An established, validated ${ }^{13} \mathrm{C}$-Spirulina platensis breath test (28-30) was used to evaluate GE. Briefly, S. platensis is a protein-rich, blue-green alga, which is sold as a dietary supplement in the United States $(31,32)$. The ${ }^{13} \mathrm{C}$ content of Spirulina is increased to $99 \%$ by growing it in a closed hydroponics chamber charged with a pure ${ }^{13} \mathrm{C}$-source. The ${ }^{13} \mathrm{C}$-labeled $S$. platensis is incorporated into an egg mix, and the ${ }^{13} \mathrm{C}$ can only be released from the algal cells after the egg mix is emptied from the stomach. The cells are digested, and the ${ }^{13} \mathrm{C}$-labeled substrates (algal protein, fat, and carbohydrate) are absorbed and metabolized. The test meal contained $27 \mathrm{~g}$ freeze-dried egg mix, 6 saltine crackers, and $180 \mathrm{~mL}$ of water with a caloric content of $223 \mathrm{kcal}(19.2 \mathrm{~g}$ carbohydrates, $12 \mathrm{~g}$ protein, and $10.9 \mathrm{~g}$ fat).

Breath samples were collected at baseline (i.e., before the meal) and at 15, 30, 45, 60, 90, 120, 150, 180, and 240 minutes after the meal in glass screwcap Exetainer® tubes (Labco Limited, High Wycombe, U.K.) using a straw to blow into the bottom of the tube to displace contained air. After re-capping the tubes, the ${ }^{13} \mathrm{CO}_{2}$ breath content was measured in a centralized laboratory (AB Diagnostics, Brentwood, TN) by Gas Isotope Ratio Mass Spectrometry. The ${ }^{13} \mathrm{C}$ enrichment was expressed as the delta per $\mathrm{mL}$ difference between the ${ }^{13} \mathrm{CO}_{2} /{ }^{12} \mathrm{CO}_{2}$ ratio of the sample and the standard. To calculate the quantity of ${ }^{13} \mathrm{C}$ appearing in breath per unit of time, delta over baseline was used where 0.0112372 is the isotopic abundance of the limestone standard (Pee Dee Belemnite) and $\mathrm{CO}_{2}$ production was corrected for age, sex, height and weight using the algorithms of Schofield et al., as described by Klein (33). The $\left[{ }^{13} \mathrm{C}\right]$ breath excretion values (kPCD units) was analyzed in all samples. These units were used to estimate GE T $1 / 2$ using validated models derived from studies in which GE was simultaneously assessed by the ${ }^{13} \mathrm{C}$-Spirulina platensis breath test and scintigraphy $(28,29)$. For this meal, the $10^{\text {th }}-90^{\text {th }}$ percentile range for GE T $1 / 2$ in healthy subjects is 50-92 minutes (29).

\section{Symptom Questionnaires}

At baseline and at every 2 weeks thereafter, GI symptoms were evaluated by the validated upper GI symptom severity index (PAGI-SYM), and the effect of GI symptoms on quality of life was evaluated by the PAGI-QOL questionnaire (34). Patients also recorded their GI symptoms every day in the validated Gastroparesis Cardinal Symptom Index-Daily Diary (GCSI-DD) $(35,36)$.

\section{Autonomic Functions}

Cardiovagal and adrenergic functions were evaluated by standardized methods during visits 1 and 3 (37). Cardiovagal functions were evaluated by heart-rate responses to deep breathing (HRDB) and the Valsalva maneuver. The HRDB was measured with the subject supine and breathing at 6 breaths per minute. For the Valsalva maneuver, the subject was rested and recumbent and was asked to maintain a column of mercury at $40 \mathrm{mmHg}$ for 15 seconds. The Valsalva ratio is the ratio of maximal-to-minimal heart rate (38). Vagal functions were 
scored by the results of HRDB and Valsalva maneuver. After the first 5 subjects were enrolled, the protocol was modified to incorporate an assessment of cardiovascular adrenergic functions by measuring blood pressure and heart rate responses to the Valsalva maneuver and the head-up tilt test (HUT) (37). The results of the autonomic battery of tests were corrected for age and gender using established norms. The Composite Autonomic Severity Score (CASS) consists of two subscores: cardiovagal (CASS-vag; 0-3); and adrenergic (CASS-adr; 0-3) (39), where 0, 1, 2, and 3 represent none, mild, moderate, and severe dysfunction, respectively. The CASS vagal score could not be computed when it was unsafe to do a Valsalva maneuver in patients with an active diabetic retinopathy.

\section{Statistical Analysis}

For each subject, the daily GCSI diary data (e.g., vomiting) were averaged per week. For the weekly diary data (PAGI-SYM and PAGI-QOL), treatment groups were compared at week 8 using analysis of covariance (ANCOVA) with the corresponding baseline value as the covariate. ANCOVA was also used to compare treatment groups for 1) HO1 protein concentration levels and activity, which were compared on days 3 and $7 ; 2$ ) gastric emptying, which was compared on days 3 and 7 ;3) parameters measured by daily diaries (i.e., GCSI total score, FDA nausea, vomiting, fullness, and pain (NVFP) composite subscore (40), and subscores for nausea/vomiting, fullness/early satiety, bloating, and upper abdominal pain); 4) autonomic functions (i.e., CASS vagal and adrenergic subscores); and 5) blood tests (safety parameters). Data were analyzed per intent-to-treat analysis using all subjects randomized. Missing values were imputed using the corresponding overall mean in all subjects with non-missing data, and an adjustment in the ANCOVA error degrees of freedom (i.e., subtracting one df for each missing value imputed) to obtain an appropriate error residual variance. Separate post hoc ANCOVA models evaluated whether treatment effects were influenced by glycated hemoglobin $(\mathrm{HbA1C})$ at baseline and a contingency table analysis (Fisher's exact test) to compare the proportion of patients who reported a 50\% or greater improvement in symptoms for 2 consecutive weekly assessments compared to baseline.

Post-hoc and exploratory associations between $\mathrm{HO} 1$ protein concentration and activity with (1) PAGI-SYM scores (GCSI total score and NVFP FDA composite score) at baseline and week 8 and (2) gastric emptying T $1 / 2$ at days 1, 3, 7, and 56 were assessed using Spearman correlation coefficients. All analyses used SAS ${ }^{\circledR}$ software (version 9.3, Cary, NC), and continuous data are reported as mean $\pm \mathrm{SEM}$, while discrete data are expressed as frequencies $(\%)$.

The sample size estimate was based on the variation in GE among a sample of 22 patients with delayed GE. In this sample, the mean (SD) for GE $\mathrm{T} 1 / 2$ estimated by scintigraphy was 192 (40) minutes. Assuming the same SD for the T $1 / 2$ values in the proposed study, a sample size of 20 patients provided approximately $80 \%$ power to detect a difference between groups ( $\mathrm{n}=10$ each) of $\geq 53$ minutes (e.g., 192 minutes for placebo vs. $₫ 39$ minutes on drug) based on a two-sample $t$-test with a two-sided alpha level of 0.05. The ANCOVA analysis provided similar power for somewhat smaller differences by incorporating relevant covariates (e.g., baseline value of GE T1/2). Such a 25\% difference in gastric emptying would be deemed 
clinically relevant and likely to be associated with improvement in gastroparesis symptoms. Therefore, the sample size proposed had sufficient power to provide clinically relevant information.

\section{Results}

\section{Participants, Study Conduct, and Completion}

Of 58 patients assessed for eligibility to participate in the study, 38 were excluded (Figure 2), leaving 20 patients who were enrolled in the study. Fourteen completed all study procedures. Nine of 11 patients randomized to hemin completed all study procedures; 1 participant dropped out before the first hemin infusion because she did not tolerate the GEBT meal, and another patient discontinued participation at week 2 because he required treatment for ongoing diabetic retinopathy. In the placebo group, 5 of 9 patients received all infusions. One patient discontinued participation at week 3 because of vomiting, diarrhea, and diabetic ketoacidosis, and one dropped out at week 4 because she did not tolerate the GEBT meal; 2 other participants received 8 of 10 placebo infusions.

\section{Baseline Clinical and Biochemical Features}

Of 20 patients, 12 had fasting plasma C-peptide concentrations less than $0.6 \mathrm{ng} / \mathrm{mL}$, indicating type 1 diabetes mellitus. The duration of diabetes mellitus was $16.3 \pm 2.4$ years. Complications of diabetes mellitus included a peripheral neuropathy (9 patients), moderate or severe autonomic neuropathy (10 patients), retinopathy (11 patients), and diabetic nephropathy (13 patients). All patients had delayed GE measured by scintigraphy. A summary of the distributions of age, sex, body mass index, and other features is given in Table 1. Note that there were no significant differences in the two groups at baseline.

\section{Effects on HO1 Protein Concentration and Activity}

Blood samples were hemolyzed for 5 and all days in 2 subjects respectively, precluding an assessment of $\mathrm{HO} 1$ activity on those days. Compared to placebo, hemin increased $\mathrm{HO} 1$ protein on days $3(P=.0002)$ and $7(P=.008)$ but not on day $56(P=.15)$; see Table 2, Figure 3. Compared to placebo, hemin increased HO1 activity on day $3(=.0003)$ but not on days 7 $(P=.18)$ or 56 ( $P=.20)$ (Table 2, Figure 4). Figures 3 and 4 show that among patients who were randomized to hemin, $\mathrm{HO} 1$ protein concentrations and activity markedly declined after switching to weekly infusions.

\section{Effects on Gastric Emptying}

The baseline GEBT demonstrated markedly delayed GE in all patients. Indeed, on average patients had only emptied an average of $52 \%$ of the test meal at 180 minutes. Compared to placebo, the effects of hemin on GE on days 1, 3, 7, and 56 were not significant (Table 2).

\section{Effects on Symptoms}

The GCSI total score declined from $3.3 \pm 0.1$ at baseline to $1.9 \pm 0.5$ at 8 weeks in the placebo group and from $3.1 \pm 0.3$ to $1.4 \pm 0.3$ in the hemin group. This difference in the GCSI total score, which was the primary symptom outcome, did not differ between treatment groups 
(Table 3). Likewise, differences in GCSI subscores and the PAGI-QOL evaluated by biweekly questionnaires (Table 3) and VAS symptom scores evaluated by daily diaries did not differ between treatment groups (Supplemental Figure). At week 1, HO1 protein concentration and activity were not correlated with GCSI total score and NVFP FDA composite score computed from daily diaries (data not shown).

\section{Effect on Autonomic Functions}

The baseline CASS vagal score was $1.7 \pm 0.3$ and the baseline adrenergic score was $1.3 \pm 0.4$, where scores of 1,2, and 3 indicate mild, moderate, and severe dysfunction, respectively (Table 2). Between baseline and day 56, the CASS vagal score increased in the placebo group and decreased in the hemin group (Table 3). However, differences were not significant. The CASS adrenergic score declined over the 8-week duration in both placebo and hemin groups; differences were not significant.

\section{Adverse Effects}

Hemin and placebo infusions were well tolerated by all subjects. Five of the participants reported headaches ( 3 placebo, 2 hemin), but none developed phlebitis. Four participants (3 placebo, 1 hemin) experienced mild to moderate nausea. Two hemin-treated subjects reported dizziness or light headedness. One subject treated with placebo had a transient maculopapular rash on both upper extremities.

After adjusting for baseline values, the platelet count on day 4 was lower $(P=.01)$ after hemin than placebo (Table 4). The hemoglobin and erythrocyte count declined after starting therapy in both groups. After adjusting for baseline values, the hemoglobin on day 7 was lower $(P<.05)$ for placebo than hemin. There were no other statistically significant changes in laboratory tests after starting therapy.

\section{Discussion}

Failure to maintain upregulation of HO1 is responsible for the loss of ICC and delayed GE in diabetic NOD mice (10). Upregulation of HO1 by hemin prevented and reversed delayed GE in this model (10). Confirming our prior findings (16), intravenous hemin increased HO1 protein concentration and activity assessed 48 hours later on average by approximately 7 fold and 10-fold, respectively, in patients with diabetic gastroparesis. On day 7, 72 hours after the infusion on day 4, protein concentration and activity were lower, albeit significantly increased compared to baseline. However, $\mathrm{HO} 1$ protein concentration and activity were not significantly increased on day 14 , which is 1 week after the last infusion, and at 1 week intervals after subsequent infusions. The early effects on $\mathrm{HO} 1$ parameters (i.e., 48 hours) in diabetic gastroparesis are comparable to the increase in $\mathrm{HO} 1$ protein concentration and activity, i.e., 4-5-fold and 15-fold, respectively, at 48 hours in healthy subjects (16), therefore likely reflecting increased $\mathrm{HO} 1$ protein synthesis. The pharmacokinetics of hemin coadministered with albumin are poorly understood. It is conceivable that hemin is gradually released from albumin, and subsequently bound to hemopexin, a transport protein that has a higher affinity for hemin than albumin and transports hemin to the liver (25). Hemopexin is 
saturated and depleted after a single dose of hemin $(4 \mathrm{mg} / \mathrm{kg})(25)$, which is lower than the dose $(3 \mathrm{mg} / \mathrm{kg})$ used in this study.

Hemin did not significantly accelerate GE or improve symptoms compared to placebo in this study. There are 3 potential but not mutually-exclusive explanations. First, it is possible that HO1 dysregulation is not involved in the pathophysiology of diabetic gastroparesis in humans. This is unlikely because studies in humans have replicated the data from mouse models with respect to changes to ICC and nNOS expression $(4,5)$, and correlation of CD206-positive HO1 containing macrophage numbers with ICC loss, which is consistent with the hypothesis that M2 macrophages are associated with ICC loss (41). Also, the length of the poly-GT repeat in the gene for HO1 (i.e., HMOX1), is associated with a higher risk of developing idiopathic and diabetic gastroparesis (42).

Second, more frequent hemin infusions or other drugs may be required. Intraperitoneal hemin was administered daily in mice resulting in a restoration of normal GE after 4.4 weeks of treatment (10). Because hemin is very expensive, it was administered less frequently-three times during the first week and at weekly intervals thereafter in this study, adapting a design of another study (NCT00467610) of intravenous hemin, for treating myelodysplastic syndrome. This resulted in failure to upregulate $\mathrm{HO} 1$ protein and activity after the switch to weekly infusions. The complex regulatory processes that control HO1 expression and three common polymorphisms in the $\mathrm{HO} 1$ gene may also explain why the response to hemin was not sustained $(43,44)$. The patients in our study were not genotyped.

Third, although inadequate levels of HO1 may be involved in diabetic gastroparesis, it is possible that these patients had other biochemical mechanisms that result in neural damage or irreversible enteric neuromuscular and/or autonomic nervous dysfunctions. Indeed, these patients had severe symptoms and markedly delayed GE at baseline. At 4 hours, they had only emptied $52 \%$ of a meal, and the total GCSI weekly diary score at baseline was 3.3. Ten patients also had moderate or severe vagal or adrenergic dysfunctions.

The effect of hemin on symptoms was not statistically significant compared with placebo (i.e., intravenous albumin). Among subjects who received placebo, the average GCSI total score declined by a clinically significant amount from 3.3 to 1.9 (i.e., by 1.2 units) over 8 weeks, which is similar to the placebo response in the trial of nortriptyline (15 weeks) (45) and the ghrelin receptor agonist TZP-101 for 4 days (46) but numerically higher than the placebo response in studies with the ghrelin receptor agonist TZP-102 for 4 weeks (47). In this study, the placebo group received albumin infusions. An intriguing possibility is that some symptoms (e.g., nausea) in patients with diabetic gastroparesis are related to orthostatic hypotension, which is alleviated by expansion of the intravascular compartment by albumin.

In conclusion, this 8-week study shows that hemin transiently but not sustainably increased HO1 protein expression. Hemin did not improve GE, autonomic functions, or upper GI symptoms compared with placebo among patients with diabetic gastroparesis. Further studies are necessary to ascertain whether more frequent hemin infusions or other drugs have a more sustained effect on HO1 and improve GE. 
Abbreviated abstract: Failure to maintain upregulation of heme oxygenase (HO1) leads to loss of interstitial cells of Cajal and delayed gastric emptying in diabetic non-obese diabetic (NOD) mice. In a single-center, double-blind, placebo-controlled, randomized clinical trial comparing intravenous hemin, prepared in albumin, to albumin alone (placebo) in 20 patients with diabetic gastroparesis, hemin increased HO1 levels up to 1 week but not thereafter. Hemin did not improve gastric emptying or gastrointestinal symptoms.

\section{Supplementary Material}

Refer to Web version on PubMed Central for supplementary material.

\section{Acknowledgments}

We thank the nursing staff of the Mayo Clinic Clinical Research and Trials Unit.

Grant Support: This study was supported by NIH Grant P01 DK068055 and by Grant Number UL1 TR000135 from the National Center for Advancing Translational Sciences (NCATS). Its contents are solely the responsibility of the authors and do not necessarily represent the official views of the NIH. We also gratefully acknowledge the support provided by Recordati Rare Diseases, who provided hemin for some participants in this study.

\section{References}

1. Camilleri M, Bharucha AE, Farrugia G. Epidemiology, mechanisms, and management of diabetic gastroparesis. Clin Gastroenterol Hepatol. 2011; 9:5-12. quiz e7. [PubMed: 20951838]

2. Bharucha A. Epidemiology and natural history of gastroparesis. Gastroenterol Clin North Am. 2015; 44:9-19. [PubMed: 25667019]

3. Camilleri M, Parkman HP, Shafi MA, Abell TL, Gerson L. American College of Gastroenterology. Clinical guideline: management of gastroparesis. Am J Gastroenterol. 2013; 108:18-37. quiz 8. [PubMed: 23147521]

4. Grover M, Bernard CE, Pasricha PJ, Lurken MS, Faussone-Pellegrini MS, Smyrk TC, Parkman HP, Abell TL, et al. Clinical-histological associations in gastroparesis: results from the Gastroparesis Clinical Research Consortium. Neurogastroenterol Motil. 2012; 24:531-9. [PubMed: 22339929]

5. Grover M, Farrugia G, Lurken MS, Bernard CE, Faussone-Pellegrini MS, Smyrk TC, Parkman HP, Abell TL, et al. Cellular changes in diabetic and idiopathic gastroparesis. Gastroenterology. 2011; 140:1575-85.e8. [PubMed: 21300066]

6. Watkins CC, Sawa A, Jaffrey S, Blackshaw S, Barrow RK, Snyder SH, Ferris CD. Insulin restores neuronal nitric oxide synthase expression and function that is lost in diabetic gastropathy. [erratum appears in J Clin Invest 2000 Sep;106(6):803] J Clin Invest. 2000; 106:373-84.

7. Vincent AM, Russell JW, Low P, Feldman EL. Oxidative stress in the pathogenesis of diabetic neuropathy. Endocr Rev. 2004; 25:612-28. [PubMed: 15294884]

8. Kashyap P, Farrugia G. Oxidative stress: key player in gastrointestinal complications of diabetes. Neurogastroenterol Motil. 2011; 23:111-4. [PubMed: 21226884]

9. Marathe CS, Horowitz M, Trahair LG, Wishart JM, Bound M, Lange K, Rayner CK, Jones KL. Relationships of Early And Late Glycemic Responses With Gastric Emptying During An Oral Glucose Tolerance Test. J Clin Endocrinol Metab. 2015; 100:3565-71. [PubMed: 26171801]

10. Choi KM, Gibbons SJ, Nguyen TV, Stoltz GJ, Lurken MS, Ordog T, Szurszewski JH, Farrugia G. Heme oxygenase-1 protects interstitial cells of Cajal from oxidative stress and reverses diabetic gastroparesis. Gastroenterology. 2008; 135:2055-64.e1. [PubMed: 18926825]

11. Gibbons SJ, Verhulst PJ, Bharucha A, Farrugia G. Review article: carbon monoxide in gastrointestinal physiology and its potential in therapeutics. Aliment Pharmacol Ther. 2013; 38:689-702. [PubMed: 23992228]

12. Abraham NG, Kappas A. Pharmacological and clinical aspects of heme oxygenase. Pharmacol Rev. 2008; 60:79-127. [PubMed: 18323402] 
13. Kashyap PC, Choi KM, Dutta N, Linden DR, Szurszewski JH, Gibbons SJ, Farrugia G. Carbon monoxide reverses diabetic gastroparesis in NOD mice. Am J Physiol Gastrointest Liver Physiol. 2010; 298:G1013-9. [PubMed: 20378827]

14. Bharucha AE, Choi KM, Saw JJ, Gibbons SJ, Farrugia GF, Carlson DA, Zinsmeister AR. Effects of aspirin \& simvastatin and aspirin, simvastatin, \& lipoic acid on heme oxygenase-1 in healthy human subjects. Neurogastroenterol Motil. 2014; 26:1437-42. [PubMed: 25093998]

15. Otterbein LE, Choi AM. Heme oxygenase: colors of defense against cellular stress. Am J Physiol Lung Cell Mol Physiol. 2000; 279:L1029-37. [PubMed: 11076792]

16. Bharucha AE, Kulkarni A, Choi KM, Camilleri M, Lempke M, Brunn GJ, Gibbons SJ, Zinsmeister AR, et al. First-in-human study demonstrating pharmacological activation of heme oxygenase-1 in humans. Clin Pharmacol Ther. 2010; 87:187-90. [PubMed: 19956091]

17. Volin L, Ruutu T, Knuutila S, Tenhunen R. Heme arginate treatment for myelodysplastic syndromes. Leuk Res. 1988; 12:423-31. [PubMed: 3379975]

18. Timonen TT, Kauma H. Therapeutic effect of heme arginate in myelodysplastic syndromes. [see comment] Eur J Haematol. 1992; 49:234-8.

19. Dellon ES, Szczepiorkowski ZM, Dzik WH, Graeme-Cook F, Ades A, Bloomer JR, Cosimi AB, Chung RT. Treatment of recurrent allograft dysfunction with intravenous hematin after liver transplantation for erythropoietic protoporphyria. Transplantation. 2002; 73:911-5. [PubMed: 11923691]

20. Rund D, Rachmilewitz E. New trends in the treatment of beta-thalassemia. Crit Rev Oncol Hematol. 2000; 33:105-18. [PubMed: 10737372]

21. Anderson KE, Bloomer JR, Bonkovsky HL, Kushner JP, Pierach CA, Pimstone NR, Desnick RJ. Recommendations for the diagnosis and treatment of the acute porphyrias. [erratum appears in Ann Intern Med. 2005 Aug 16;143(4):316] Ann Intern Med. 2005; 142:439-50.

22. Zigmond A, Snaith R. The hospital anxiety and depression scale. Acta Psychiatr Scand. 1983; 67:361-70. [PubMed: 6880820]

23. Talley NJ, Phillips SF, Wiltgen CM, Zinsmeister AR, Melton LJ. Assessment of functional gastrointestinal disease: the bowel disease questionnaire. Mayo Clin Proc. 1990; 65:1456-79. [PubMed: 2232900]

24. Camilleri M, Iturrino J, Bharucha AE, Burton D, Shin A, Jeong ID, Zinsmeister AR. Performance characteristics of scintigraphic measurement of gastric emptying of solids in healthy participants. Neurogastroenterol Motil. 2012; 24:1076-e562. [PubMed: 22747676]

25. Siegert SWK, Holt RJ. Physicochemical properties, pharmacokinetics, and pharmacodynamics of intravenous hematin: a literature review. Adv Ther. 2008; 25:842-57. [PubMed: 18777015]

26. Bonkovsky HL, Healey JF, Lourie AN, Gerron GG. Intravenous heme-albumin in acute intermittent porphyria: evidence for repletion of hepatic hemoproteins and regulatory heme pools. Am J Gastroenterol. 1991; 86:1050-6. [PubMed: 1713408]

27. Nath KA, Balla G, Vercellotti GM, Balla J, Jacob HS, Levitt MD, Rosenberg ME. Induction of heme oxygenase is a rapid, protective response in rhabdomyolysis in the rat. J Clin Invest. 1992; 90:267-70. [PubMed: 1634613]

28. Szarka LA, Camilleri M, Vella A, Burton D, Baxter K, Simonson J, Zinsmeister AR. A stable isotope breath test with a standard meal for abnormal gastric emptying solids in the clinic and in research. Clin Gastroenterol Hepatol. 2008; 6:635-43. [PubMed: 18406670]

29. Bharucha AE, Camilleri M, Veil E, Burton D, Zinsmeister AR. Comprehensive assessment of gastric emptying with a stable isotope breath test. Neurogastroenterol Motil. 2013; 25:e60-9. [PubMed: 23216872]

30. Bharucha AE, Kudva YC, Basu A, Camilleri M, Low PA, Vella A, Zinsmeister AR. Relationship Between Glycemic Control And Gastric Emptying In Poorly Controlled Type 2 Diabetes. Clin Gastroenterol Hepatol. 2014; 13:466-76.e1. [PubMed: 25041866]

31. Ciferri O. Spirulina, the edible microorganism. Microbiol Rev. 1983; 47:551-78. [PubMed: 6420655]

32. Ciferri O, Tiboni O. The biochemistry and industrial potential of Spirulina. Annu Rev Microbiol. 1985; 39:503-26. [PubMed: 3933408] 
33. Klein PD. Clinical applications of 13CO2 measurements. Fed Proc. 1982; 41:2698-701. [PubMed: 6809498]

34. Rentz AM, Kahrilas P, Stanghellini V, Tack J, Talley NJ, de la Loge C, Trudeau E, Dubois D, et al. Development and psychometric evaluation of the patient assessment of upper gastrointestinal symptom severity index (PAGI-SYM) in patients with upper gastrointestinal disorders. Qual Life Res. 2004; 13:1737-49. [PubMed: 15651544]

35. Revicki DA, Camilleri M, Kuo B, Norton NJ, Murray L, Palsgrove A, Parkman HP. Development and content validity of a gastroparesis cardinal symptom index daily diary. Aliment Pharmacol Ther. 2009; 30:670-80. [PubMed: 19558608]

36. Revicki DA, Camilleri M, Kuo B, Szarka LA, McCormack J, Parkman HP. Evaluating symptom outcomes in gastroparesis clinical trials: validity and responsiveness of the Gastroparesis Cardinal Symptom Index-Daily Diary (GCSI-DD). Neurogastroenterol Motil. 2012; 24:456-63. [PubMed: 22284754]

37. Low PA. Autonomic nervous system function. J Clin Neurophysiol. 1993; 10:14-27. [PubMed: 8458992]

38. Low PA, Denq JC, Opfer-Gehrking TL, Dyck PJ, O'Brien PC, Slezak JM. Effect of age and gender on sudomotor and cardiovagal function and blood pressure response to tilt in normal subjects. Muscle Nerve. 1997; 20:1561-8. [PubMed: 9390669]

39. Low PA. Composite autonomic scoring scale for laboratory quantification of generalized autonomic failure. Mayo Clin Proc. 1993; 68:748-52. [PubMed: 8392653]

40. Bharucha AE, Batey-Schaefer B, Cleary PA, Murray JA, Cowie C, Lorenzi G, Driscoll M, Harth J, et al. Delayed Gastric Emptying is Associated with Early and Long-Term Hyperglycemia in Type 1 Diabetes Mellitus. Gastroenterology. 2015; 149:330-9. [PubMed: 25980755]

41. Zinman B, Hoogwerf BJ, Duran Garcia S, Milton DR, Giaconia JM, Kim DD, Trautmann ME, Brodows RG. The effect of adding exenatide to a thiazolidinedione in suboptimally controlled type 2 diabetes: a randomized trial.[Erratum appears in Ann Intern Med. 2007 Jun 19;146(12):896], [Summary for patients in Ann Intern Med. 2007 Apr 3;146(7):I18; PMID: 17404346] Ann Intern Med. 2007; 146:477-85.

42. Gibbons SJ, Choi KM, Wilson L, Tonascia J, Pasricha PJ, Farrugia G. 69 Gastroparesis Is Associated With Expanded Polynucleotide Repeats in the Promoter Region Upstream of the Transcriptional Start Site for the Heme Oxygenase 1 (HO1) Gene. Gastroenterology. 146:S-19.

43. Noel A, Tyrrell RM. Development of refractoriness of induced human heme oxygenase-1 gene expression to reinduction by UVA irradiation and hemin. Photochem Photobiol. 1997; 66:456-63. [PubMed: 9337616]

44. Exner M, Minar E, Wagner O, Schillinger M. The role of heme oxygenase-1 promoter polymorphisms in human disease. Free Radic Biol Med. 2004; 37:1097-104. [PubMed: 15451051]

45. Parkman HP, Van Natta ML, Abell TL, McCallum RW, Sarosiek I, Nguyen L, Snape WJ, Koch $\mathrm{KL}$, et al. Effect of nortriptyline on symptoms of idiopathic gastroparesis: the NORIG randomized clinical trial. JAMA. 2013; 310:2640-9. [PubMed: 24368464]

46. Ejskjaer N, Dimcevski G, Wo J, Hellstrom PM, Gormsen LC, Sarosiek I, Softeland E, Nowak T, et al. Safety and efficacy of ghrelin agonist TZP-101 in relieving symptoms in patients with diabetic gastroparesis: a randomized, placebo-controlled study. Neurogastroenterol Motil. 2010; 22:1069e281. [PubMed: 20524987]

47. Ejskjaer N, Wo JM, Esfandyari T, Mazen Jamal M, Dimcevski G, Tarnow L, Malik RA, Hellstrom PM, et al. A phase 2a, randomized, double-blind 28-day study of TZP-102 a ghrelin receptor agonist for diabetic gastroparesis. Neurogastroenterol Motil. 2013; 25:e140-50. [PubMed: 23279217]

\section{Abbreviations}

$\begin{array}{ll}\text { ICC } & \text { interstitial cells of Cajal } \\ \text { HO1 } & \text { heme oxygenase } 1\end{array}$

Neurogastroenterol Motil. Author manuscript; available in PMC 2017 November 01. 
NOD non-obese diabetic

CO carbon monoxide 


\section{Key Points}

- $\quad$ This study suggests that hemin increased HO1 protein on days 3 and 7 and $\mathrm{HO} 1$ activity on day 3 but did not improve gastric emptying, autonomic functions or gastrointestinal symptoms in patients with diabetic gastroparesis.

- $\quad$ The aims of this study were to compare effects of hemin and placebo infusions on $\mathrm{HO} 1$ activity and protein, gastric emptying, autonomic function, and gastrointestinal symptoms in diabetic gastroparesis.

- Intravenous hemin, prepared in albumin, or albumin alone (placebo) was administered on days 1,3 , and 7 , followed by weekly infusions for 7 weeks in 20 patients with diabetic gastroparesis. Assessments included blood tests for $\mathrm{HO} 1$ protein and enzyme activity levels, gastric emptying with ${ }^{13} \mathrm{C}$-spirulina breath test, autonomic functions (baseline and end), and gastrointestinal symptoms every 2 weeks. 
Gastric emptying

Panhematin infusion

Autonomic tests

Blood tests

GCSI Daily Diary

Biweekly questionnaire
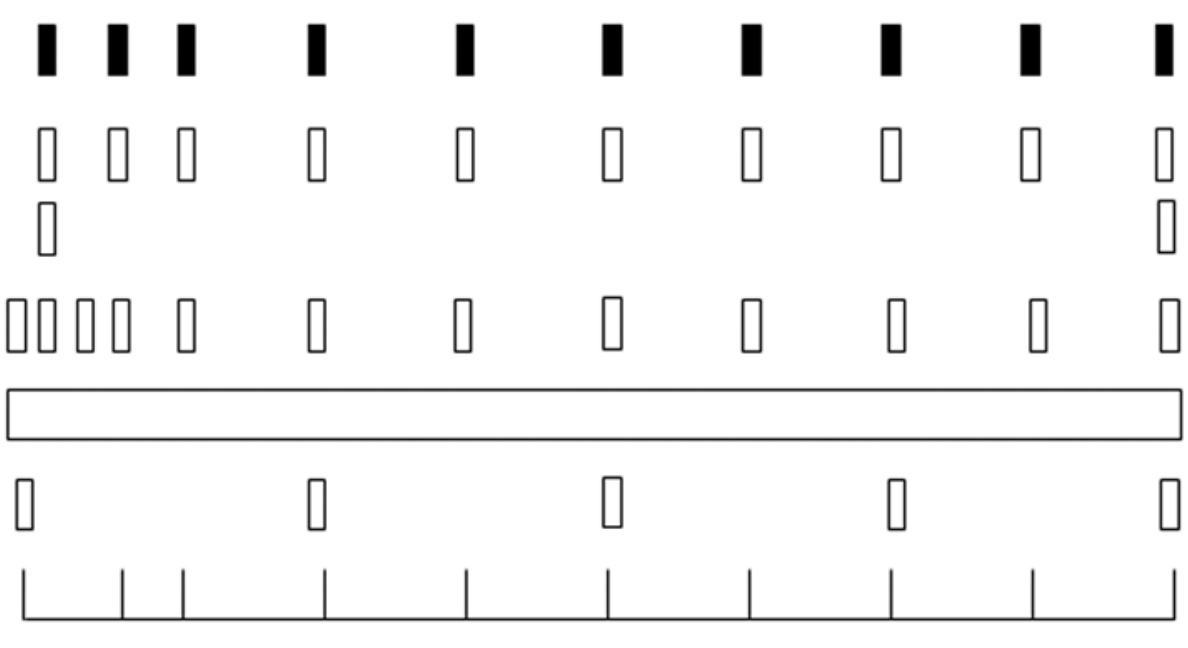

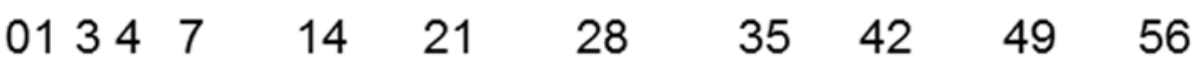
Days

Figure 1. Timing of study procedures 


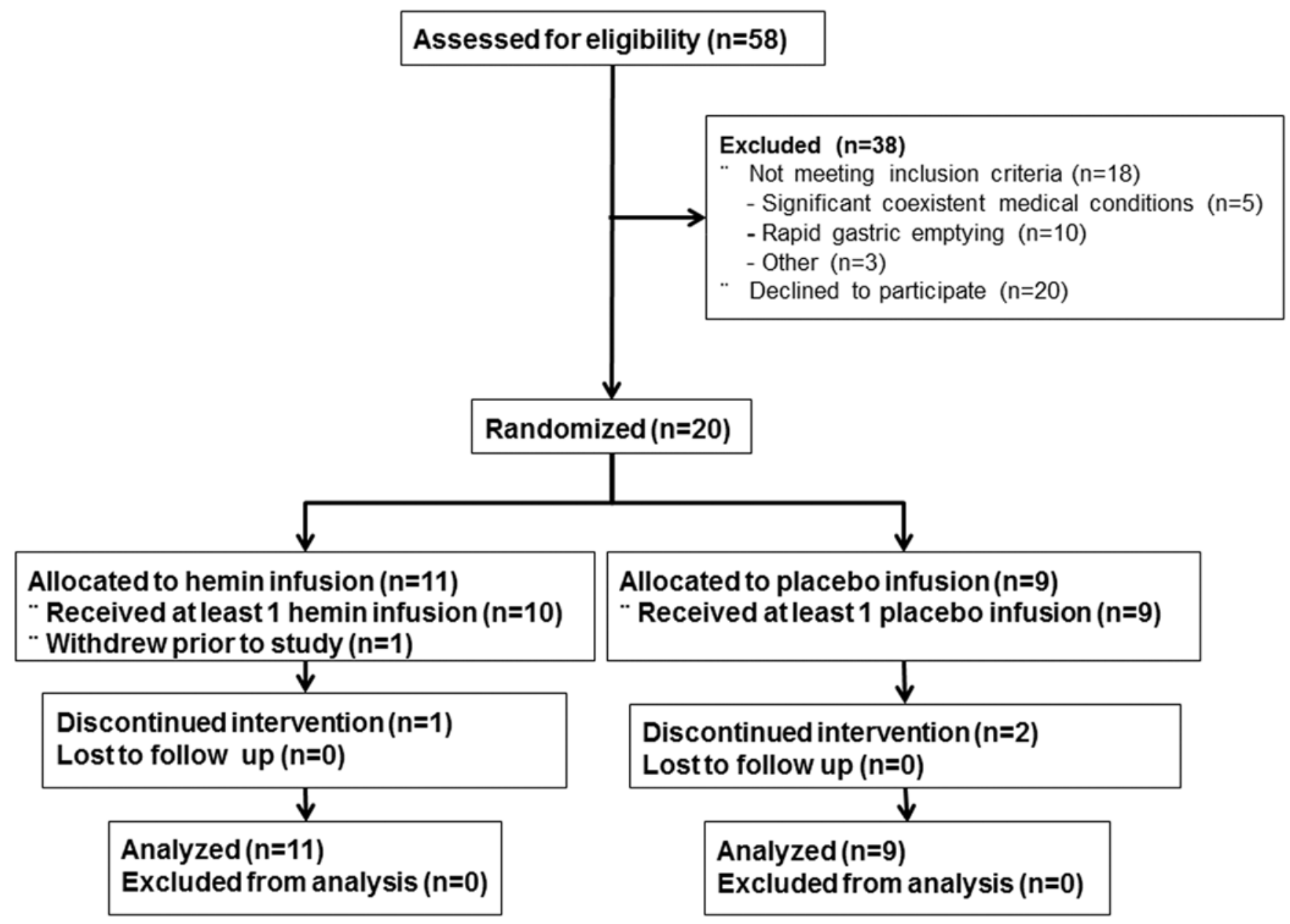

Figure 2. Study flow 


\section{Venous plasma HO-1 protein concentration $(\mathrm{ng} / \mathrm{ml})$}

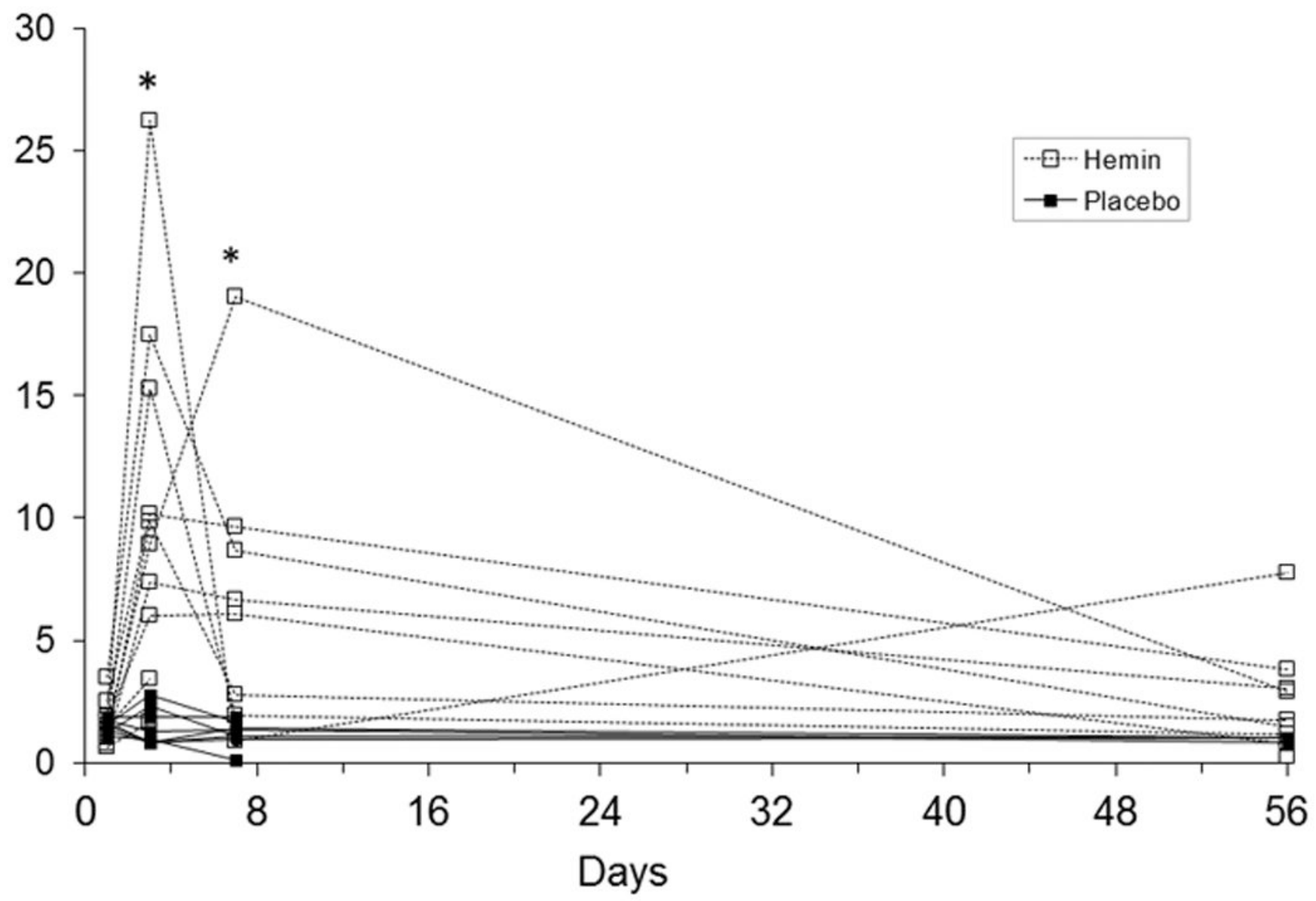

Figure 3. Effect of hemin and placebo on venous plasma HO1 protein concentrations plotted for each participant. * Compared to placebo, hemin increased HO1 protein on days $3(P=.0002)$ and $7(P=.008)$ but not day 56 


\section{Venous leukocyte HO-1 activity (pmol bilirubin/mg/h)}

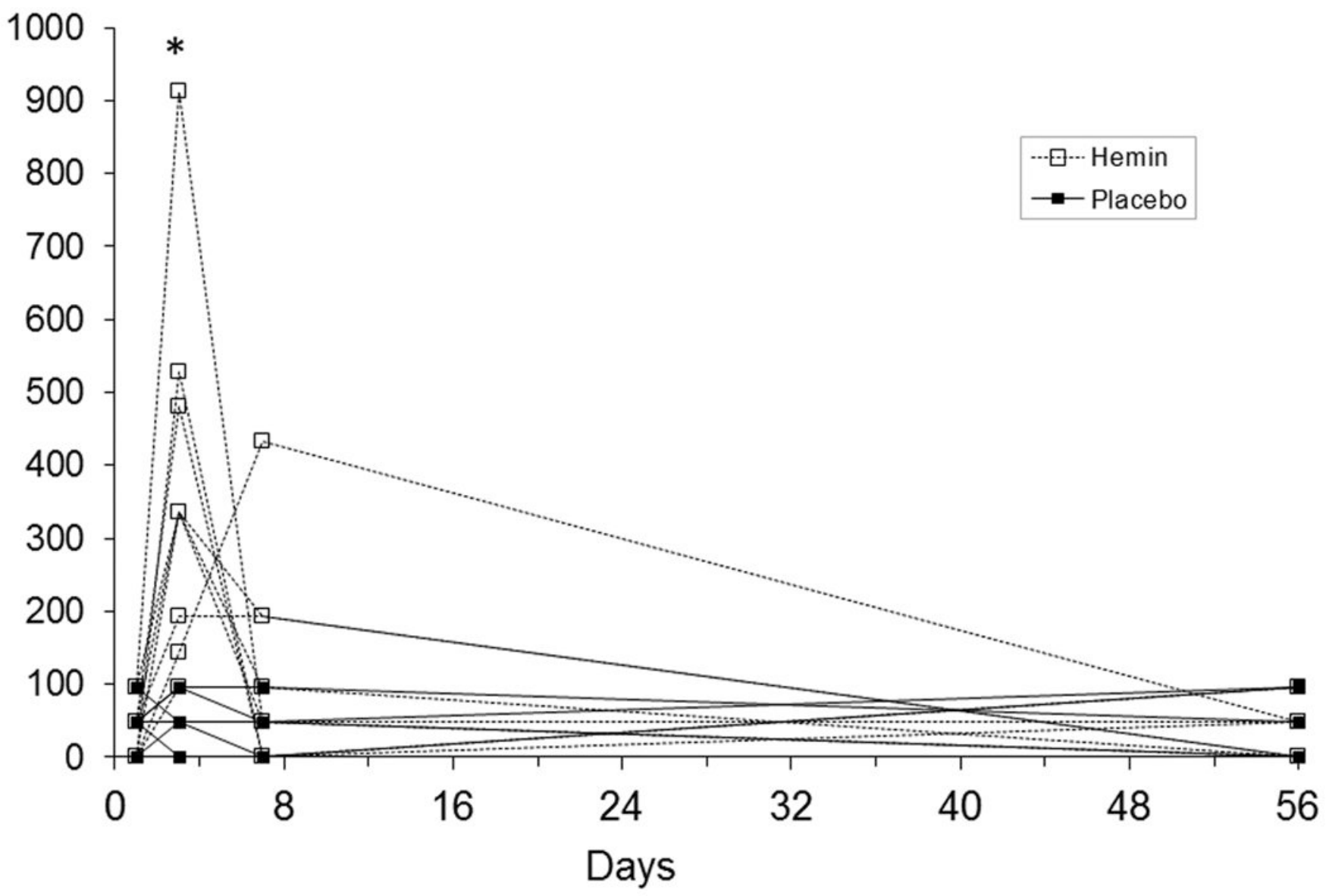

Figure 4. Effect of hemin and placebo on venous leukocyte HO1 protein activity plotted for each participant. Compared to placebo, hemin increased $\mathrm{HO1}$ activity on day $3(P=.0003)$ but not on days 7 or 56 
Table 1

Demographics and Baseline Clinical Features ${ }^{a}$

\begin{tabular}{|l|c|c|}
\hline & Placebo & Hemin \\
\hline Patients, $\mathrm{n}$ & 9 & 11 \\
\hline Age, yr & $35.3 \pm 5.0$ & $45.5 \pm 4.8$ \\
\hline Women, $\mathrm{n}$ & 9 & 9 \\
\hline Body mass index, $\mathrm{kg} / \mathrm{m}^{2}$ & $22.9 \pm 1.5$ & $26.5 \pm 2.2$ \\
\hline Plasma C-peptide concentration less than 200 pmol/L, $\mathrm{n}$ & 7 & 6 \\
\hline Duration of DM, years & $14.1 \pm 3.5$ & $18.1 \pm 3.2$ \\
\hline HbA1c, \% & $8.7 \pm 0.7$ & $8.3 \pm 0.4$ \\
\hline Diabetic peripheral neuropathy, No & 5 & 4 \\
\hline Moderate or severe cardiovagal or adrenergic dysfunction, Yes & 4 & 5 \\
\hline Diabetic retinopathy, No & 7 & 4 \\
\hline Diabetic nephropathy, No & 7 & 6 \\
\hline Gastric emptying by scintigraphy prior to current study & & \\
\hline 1 hour (\%) & $11.7 \pm 1.9$ & $17.3 \pm 1.8$ \\
\hline 2 hours (\%) & $21.6 \pm 3.8$ & $32.2 \pm 2.3$ \\
\hline 4 hours (\%) & $60.4 \pm 5.6$ & $61.7 \pm 4.2$ \\
\hline
\end{tabular}

Abbreviations: DM, Diabetes Mellitus

${ }^{a}$ Data shown as number or mean \pm SEM. 
Table 2

Effects of Hemin and Placebo Infusions on Heme-Oxygenase-1, Gastric Emptying, and Autonomic Functions ${ }^{a}$

\begin{tabular}{|c|c|c|}
\hline & Placebo & Hemin \\
\hline \multicolumn{3}{|c|}{ Venous plasma HO1 protein concentrations $(n g / m L) b$} \\
\hline Baseline $(\mathrm{n}=19)$ & $1.5 \pm 0.1$ & $1.6 \pm 0.3$ \\
\hline Day $3(n=18)$ & $1.5 \pm 0.3$ & $10.6 \pm 2.3^{c}$ \\
\hline Day $7(\mathrm{n}=16)$ & $1.2 \pm 0.2$ & $7.0 \pm 2.1^{d}$ \\
\hline Day $56(n=13)$ & $1.0 \pm 0.1$ & $2.6 \pm 0.8$ \\
\hline \multicolumn{3}{|c|}{ Venous monocyte HO1 activity (pmol bilirubin/mg/h) } \\
\hline Baseline $(\mathrm{n}=18)$ & $42.1 \pm 10.9$ & $38.5 \pm 12.0$ \\
\hline Day $3(n=17)$ & $48.1 \pm 12.9$ & $373.9 \pm 82.8^{c}$ \\
\hline Day $7(n=16)$ & $36.1 \pm 12.0$ & $126.2 \pm 51.3$ \\
\hline Day $56(n=12)$ & $60.1 \pm 23.0$ & $30.1 \pm 12.7$ \\
\hline \multicolumn{3}{|l|}{ Gastric emptying, $t_{50}(\min )$} \\
\hline Baseline (n=19) & $160.1 \pm 16.3$ & $161.8 \pm 6.7$ \\
\hline Day $3(n=19)$ & $155.4 \pm 16.5$ & $155.6 \pm 9.1$ \\
\hline Day $7(\mathrm{n}=17)$ & $155.4 \pm 15.0$ & $154.0 \pm 6.5$ \\
\hline Day $56(n=15)$ & $153.4 \pm 16.4$ & $161.2 \pm 6.2$ \\
\hline \multicolumn{3}{|l|}{ Autonomic functions } \\
\hline CASS vagal score - baseline $(n=17)$ & $1.7 \pm 1.1$ & $1.6 \pm 0.5$ \\
\hline CASS vagal score - day $56(n=17)$ & $1.9 \pm 0.4$ & $1.2 \pm 0.4$ \\
\hline CASS adrenergic score - baseline $(n=11)$ & $1.6 \pm 1.3$ & $1.0 \pm 0.5$ \\
\hline CASS adrenergic score - day $56(n=11)$ & $1.2 \pm 0.6$ & $0.6 \pm 0.4$ \\
\hline
\end{tabular}

Abbreviations: CASS, Composite Autonomic Severity Score; HO1, heme oxygenase

${ }^{a}$ Data shown as mean \pm SEM.

$b_{\text {Refers to number of subjects in whom assessments could be performed, data were available, and analyzed }}$

$c_{P<0.001 \text { and }}$

$d_{P<0.01 \text { versus placebo }}$ 
Table 3

Effects of Hemin and Placebo Infusions on Gastroparesis Symptoms and Quality of Life Evaluated Every Two Weeks

\begin{tabular}{|c|c|c|c|c|}
\hline Scores & Baseline Placebo (n=9) & 8 weeks Placebo $(n=7)$ & Baseline Hemin $(n=9)$ & 8 weeks Hemin $(n=9)$ \\
\hline \multicolumn{5}{|l|}{ PAGI-SYM } \\
\hline GCSI total score ${ }^{*}$ & $3.3 \pm 0.1$ & $1.9 \pm 0.5$ & $3.1 \pm 0.3$ & $1.4 \pm 0.3$ \\
\hline Nausea/vomiting subscore ${ }^{*}$ & $3.2 \pm 0.4$ & $1.3 \pm 0.4$ & $2.9 \pm 0.6$ & $1.3 \pm 0.4$ \\
\hline Fullness/early satiety subscore ${ }^{*}$ & $3.4 \pm 0.3$ & $2.1 \pm 0.5$ & $3.8 \pm 0.3$ & $1.9 \pm 0.4$ \\
\hline Bloating subscore ${ }^{*}$ & $3.4 \pm 0.4$ & $2.4 \pm 0.7$ & $2.6 \pm 0.5$ & $1.0 \pm 0.3$ \\
\hline Upper abdominal pain subscore ${ }^{*}$ & $2.8 \pm 0.6$ & $1.7 \pm 0.6$ & $3.7 \pm 0.4$ & $1.4 \pm 0.4$ \\
\hline Lower abdominal pain subscore ${ }^{*}$ & $1.9 \pm 0.4$ & $1.4 \pm 0.5$ & $2.6 \pm 0.4$ & $1.3 \pm 0.4$ \\
\hline Heartburn/regurgitation subscore ${ }^{*}$ & $1.8 \pm 0.4$ & $0.9 \pm 0.5$ & $2.0 \pm 0.4$ & $1.0 \pm 0.4$ \\
\hline FDA NVFP composite subscore ${ }^{*}$ & $3.3 \pm 0.2$ & $1.7 \pm 0.4$ & $3.4 \pm 0.4$ & $1.5 \pm 0.4$ \\
\hline \multicolumn{5}{|l|}{ Dyspepsia Severity Ratings ${ }^{* * *}$} \\
\hline Fullness & $59.8 \pm 10.2$ & $43.0 \pm 14.3$ & $47.9 \pm 10.2$ & $31.4 \pm 9.0$ \\
\hline Inability to finish a regular meal & $54.7 \pm 10.2$ & $36.2 \pm 14.5$ & $36.6 \pm 9.7$ & $30.9 \pm 10.5$ \\
\hline Bloating in upper abdomen & $46.2 \pm 14.0$ & $51.7 \pm 16.8$ & $24.0 \pm 11.2$ & $27.2 \pm 7.8$ \\
\hline Discomfort in upper abdomen & $44.0 \pm 12.6$ & $41.9 \pm 13.3$ & $45.8 \pm 9.8$ & $34.0 \pm 9.5$ \\
\hline Pain/ache in upper abdomen & $45.1 \pm 12.8$ & $40.6 \pm 13.6$ & $37.3 \pm 11.5$ & $29.3 \pm 10.0$ \\
\hline Nausea after meals & $52.4 \pm 10.8$ & $22.1 \pm 8.3$ & $41.9 \pm 11.1$ & $36.1 \pm 10.5$ \\
\hline \multicolumn{5}{|l|}{ PAGI-QOL } \\
\hline Total score & $1.8 \pm 0.3$ & $3.1 \pm 0.6$ & $2.3 \pm 0.4$ & $3.7 \pm 0.4$ \\
\hline Daily activities & $1.5 \pm 0.4$ & $2.9 \pm 0.6$ & $1.9 \pm 0.4$ & $3.2 \pm 0.5$ \\
\hline Diet/food habits & $1.4 \pm 0.3$ & $3.1 \pm 0.5$ & $3.1 \pm 0.5$ & $2.9 \pm 0.5$ \\
\hline
\end{tabular}

Abbreviations: FDA NVFP, US Food and Drug Administration Nausea, Vomiting, Fullness, and Pain; GCSI, Gastroparesis Cardinal Symptom Index; PAGI-QOL, Patient Assessment of Upper Gastrointestinal Disorders-Quality of Life; PAGI-SYM, Patient Assessment of Upper Gastrointestinal Disorders-Symptoms; GCSI, Gastroparesis Cardinal Symptom Index.

* Components coded 0 (no symptoms) to 5 (very severe). GCSI total score is the average of 9 components from the nausea/vomiting, fullness/early satiety, and bloating subscores. These individual subscores are averages of 3, 4, and 2 components, respectively. Subscores for upper and lower abdominal pain, heartburn/regurgitation and FDA NVFP composite are averages of 2, 2, 7, and 4 components, respectively.

**

Components coded on the VAS scale of 0 (no severity) to 100 (worst ever).

***

Components coded 0 (lowest quality of life) to 5 (highest quality of life). Total score is the sum of all 30 survey components. Subscores for daily activities and diet/food habits are sums of 10 and 7 components, respectively.

Data shown as mean \pm SEM. 
롤

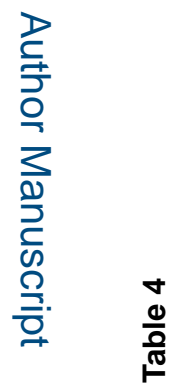

要

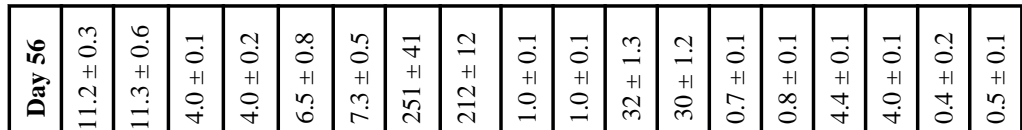

量

을

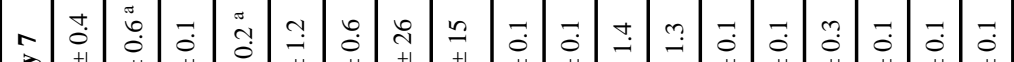

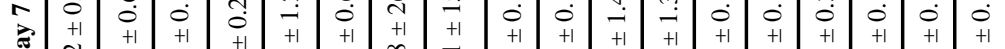

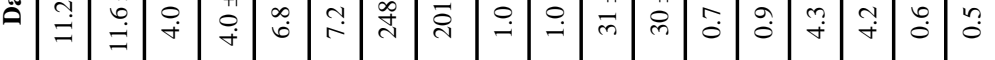

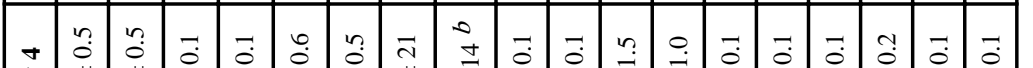

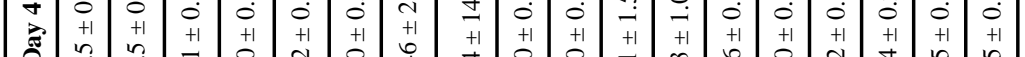

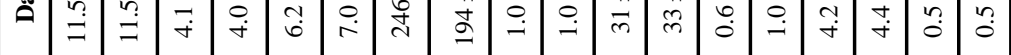

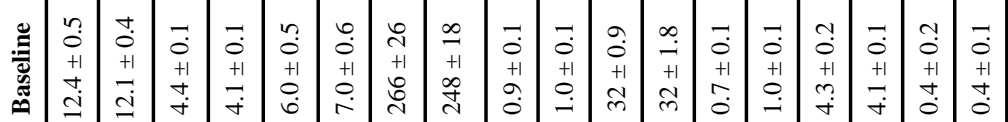

\begin{tabular}{|c|c|c|c|c|c|c|c|c|c|c|c|c|c|c|c|c|}
\hline$\Xi$ & 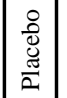 & 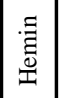 & 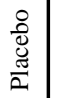 & 焉 & 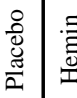 & 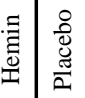 & 訔 & $\mid$\begin{tabular}{|c|} 
\\
$\frac{0}{0}$ \\
$\frac{\pi}{2}$ \\
\end{tabular} & 㽦 & 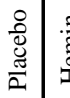 & 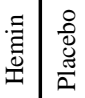 & \begin{tabular}{|l|} 
音 \\
咅
\end{tabular} & 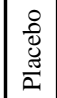 & 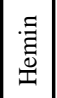 & 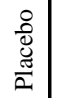 & 童 \\
\hline & 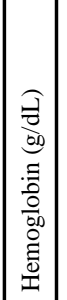 & & 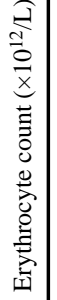 & & 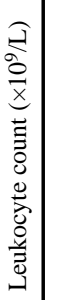 & 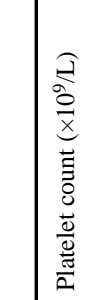 & & 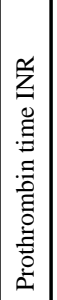 & & 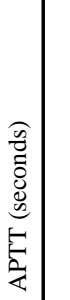 & 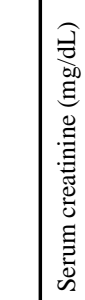 & & 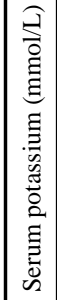 & & 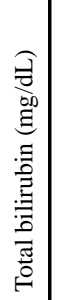 & \\
\hline
\end{tabular}

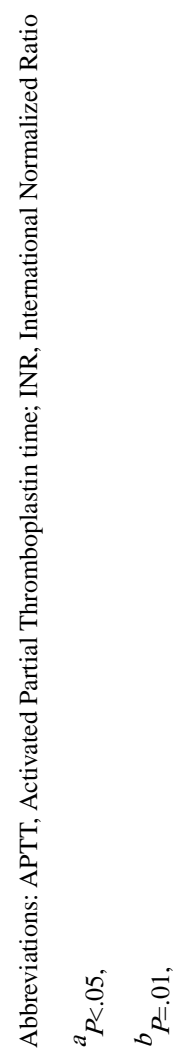

Neurogastroenterol Motil. Author manuscript; available in PMC 2017 November 01. 